\title{
BDNF Val66Met Polymorphism Interacts with Sleep Consolidation to Predict Ability to Create New Declarative Memories
}

\author{
@Nadia Gosselin, ${ }^{1,2}$ Louis De Beaumont, ${ }^{1,5}$ @Katia Gagnon, ${ }^{1,6}$ @Andrée-Ann Baril, ${ }^{1,3}$ Valérie Mongrain, ${ }^{1,4}$ Hélène Blais, ${ }^{1}$ \\ Jacques Montplaisir, ${ }^{1,3}$ Jean-François Gagnon, ${ }^{1,6}$ Sandra Pelleieux, ${ }^{7,8}$ Judes Poirier, ${ }^{7,8}$ and ${ }^{\circ}$ Julie Carrier ${ }^{1,2}$ \\ ${ }^{1}$ Center for Advanced Research in Sleep Medicine and Research Center, Hôpital du Sacré-Coeur de Montréal, Montréal, Québec, H4J 1C5, Canada, \\ Departments of ${ }^{2}$ Psychology, ${ }^{3}$ Psychiatry, and ${ }^{4}$ Neuroscience, Université de Montréal, Montréal, Québec, H3C 3J7, Canada, ${ }^{5}$ Department of Psychology, \\ Université du Québec à Trois-Rivières, Trois-Rivières, Québec, G9A 5H7, Canada, ${ }^{6}$ Department of Psychology, Université du Québec à Montréal, Montreal, \\ Québec, H3C 3P8, Canada, ${ }^{7}$ Centre for Studies on Prevention of Alzheimer's Disease, Douglas Institute, Verdun, Québec, H4H 1R3, Canada, and \\ ${ }^{8}$ Department of Psychiatry and Medicine, McGill University, Montréal, Québec, H3A 0G4, Canada
}

It is hypothesized that a fundamental function of sleep is to restore an individual's day-to-day ability to learn and to constantly adapt to a changing environment through brain plasticity. Brain-derived neurotrophic factor (BDNF) is among the key regulators that shape brain plasticity. However, advancing age and carrying the BDNF Met allele were both identified as factors that potentially reduce BDNF secretion, brain plasticity, and memory. Here, we investigated the moderating role of BDNF polymorphism on sleep and next-morning learning ability in 107 nondemented individuals who were between 55 and 84 years of age. All subjects were tested with 1 night of in-laboratory polysomnography followed by a cognitive evaluation the next morning. We found that in subjects carrying the $B D N F$ Val66Val polymorphism, consolidated sleep was associated with significantly better performance on hippocampus-dependent episodic memory tasks the next morning ( $\beta$-values from 0.290 to $0.434, p \leq 0.01)$. In subjects carrying at least one copy of the $B D N F$ Met allele, a more consolidated sleep was not associated with better memory performance in most memory tests $(\beta$-values from -0.309 to $-0.392, p$ values from 0.06 to 0.15$)$. Strikingly, increased sleep consolidation was associated with poorer performance in learning a short story presented verbally in Met allele carriers $(\beta=-0.585, p=0.005)$. This study provides new evidence regarding the interacting roles of consolidated sleep and BDNF polymorphism in the ability to learn and stresses the importance of considering BDNF polymorphism when studying how sleep affects cognition.

Key words: aging; brain derived neurotrophic factor; cognition; memory; sleep; slow-wave sleep

\section{Significance Statement}

Individuals with the BDNF Val/Val (valine allele) polymorphism showed better memory performance after a night of consolidated sleep. However, we observed that middle-aged and older individuals who are carriers of the BDNF Met allele displayed no positive association between sleep quality and their ability to learn the next morning. This interaction between sleep and $B D N F$ polymorphism was more salient for hippocampus-dependent tasks than for other cognitive tasks. Our results support the hypothesis that reduced activity-dependent secretion of BDNF impairs the benefits of sleep on synaptic plasticity and next-day memory. Our work advances the field by revealing new evidence of a clear genetic heterogeneity in how sleep consolidation contributes to the ability to learn.

\section{Introduction}

There is strong evidence supporting the fundamental role of sleep in brain plasticity, memory, and learning (Diekelmann and Born,

Received Dec. 11, 2015; revised June 20, 2016; accepted June 23, 2016.

Author contributions: N.G., L.D.B., K.G., A.-A.B., J.M., and J.-F.G. designed research; N.G., K.G., A.-A.B., and H.B. performed research; N.G., L.D.B., K.G., A.-A.B., H.B., and S.P. analyzed data; N.G., L.D.B., K.G., A.-A.B., V.M., J.M., J.-F.G., J.P., and J.C. wrote the paper.
2010). Sleep facilitates the consolidation of new information or abilities learned the previous day (Walker et al., 2002; Peigneux et

This work was supported by the Canadian Institutes of Health Research (operating grants to N.G., J.M., J.-F.G. L.D.B., and J.P., a salary award to J.-F.G., and a studentship award to A.-A.B.) and by the Fonds de recherche du Québec-Santé (salary awards to N.G., L.D.B., V.M., J.-F.G., S.P., and J.C.). J.-F.G. holds the Canadian Research Chair in Cognitive Decline in Pathological Aging, while J.M. holds the Canadian Research Chair on Sleep Medicine. We thank Gaétan Poirier, Dr. Jean Paquet, Caroline D'Aragon, Danièle Legault, Marie-Josée Quinn, Dr. Marjolaine Lafortune, 
al., 2004). The characteristics of sleep also predict the ability to learn new material after the sleep episode (Mander et al., 2011; Lafortune et al., 2014), and total sleep deprivation impedes subsequent encoding in episodic memory (Drummond et al., 2000; Yoo et al., 2007). The synaptic homeostasis hypothesis suggests that in response to learning, synaptic potentiation increases in the cortex and the hippocampus during wakefulness, which eventually saturates the ability to learn (Tononi and Cirelli, 2014). The same authors proposed that sleep-particularly slow-wave activity (SWA) occurring during non-rapid eye movement (NREM) sleep-restores the ability to learn by depressing synaptic strength. Suppression of SWA before learning was shown to affect hippocampal activity and next-day memory even when total sleep time is not reduced (Van Der Werf et al., 2009, 2011).

Sleep consolidation is another sleep characteristic that plays a major role in memory and synaptic plasticity. Rodent studies suggest that sleep fragmentation, independently of sleep duration, impairs long-term potentiation and the ability to learn (Tartar et al., 2006; Wallace et al., 2015). Moreover, a minimal unit of uninterrupted sleep, or sleep bout, is necessary to improve nextday learning (Rolls et al., 2011).

The availability of brain-derived neurotrophic factor (BDNF), a secretory peptide, is crucial for synaptic plasticity (Kang and Schuman, 1995). BDNF is released in response to neural activity and plays a key role in activity-dependent synaptic strengthening (Korte et al., 1995). One factor that intrinsically modulates the availability of BDNF in the human brain is the rs6265 single nucleotide polymorphism in the BDNF gene. In Caucasians, 25$35 \%$ of the population carries a valine (Val) to methionine (Met) substitution at codon 66 (referred to as Met carriers) and has reduced activity-dependent BDNF secretion compared with homozygous BDNF Val allele carriers (referred to as Val/Val carriers; Egan et al., 2003). Several studies have linked reduced BDNF secretion in Met carriers with lower synaptic plasticity and poorer memory (Baj et al., 2013), although significant inconsistencies exist (Mandelman and Grigorenko, 2012). In comparison with $\mathrm{Val} / \mathrm{Val}$ carriers, it was suggested that Met carriers experience growing impairment on memory tasks as they age (Kennedy et al., 2015), making the aging population particularly appealing to understanding how the BDNF Met allele affects memory.

It is unknown whether sleep and $B D N F$ polymorphism interact to predict the ability to encode new episodic memory the next morning. The present study aims to ascertain whether BDNF polymorphism moderates the association between sleep (more specifically, NREM SWA, and sleep consolidation) and performance on subsequent episodic declarative memory tasks. Given that sleep plays a crucial role in memory and synaptic plasticity, and that the BDNF Met allele was shown to reduce brain plasticity, we hypothesized that the positive effect of sleep on new learning the next morning would be significantly reduced among Met carriers compared with Val/Val carriers.

Nazmiye Uzun, Dr. Catherine Chapados-Noreau, Dr. Frédérique Escudier, and the staff of the Center for Advanced Research in Sleep Medicine of Hôpital du Sacré-Coeur de Montréal for their contribution to subject testing and data analysis. We also thank Louise Théroux and Mélanie Wellman for their contribution to genotyping analyses.

The authors declare no competing financial interests.

Correspondence should be addressed to Dr. Nadia Gosselin, Center for Advanced Research in Sleep Medicine, Hôpital du Sacré-Coeur de Montréal, 5400 Gouin Boulevard West, Room E-0330, Montréal, QC H4J 1C5, Canada. E-mail: nadia.gosselin@umontreal.ca.

DOI:10.1523/JNEUROSCI.4432-15.2016

Copyright $\odot 2016$ the authors $\quad 0270-6474 / 16 / 368391-09 \$ 15.00 / 0$
Table 1. Characteristics of $\mathrm{Val} / \mathrm{Val}$ and Met carriers

\begin{tabular}{lcccl}
\hline Variables & $\begin{array}{c}\text { Val/Val carriers } \\
(n=79)\end{array}$ & $\begin{array}{c}\text { Met carriers } \\
(n=28)\end{array}$ & $\begin{array}{c}t / \chi^{2} \\
\text { values }\end{array}$ & $\begin{array}{l}p \\
\text { values }\end{array}$ \\
\hline Age (years) & $63.5 \pm 6.3$ & $63.2 \pm 6.5$ & 0.2 & n.s. \\
Male sex (\%) & 78.4 & 75 & 0.14 & n.s. \\
Education (years) & $15.8 \pm 4.0$ & $14.5 \pm 2.8$ & 1.8 & n.s. \\
Body mass index $\left(\mathrm{kg} / \mathrm{m}^{2}\right)$ & $27.0 \pm 6.0$ & $27.7 \pm 3.9$ & -0.5 & n.s. \\
Vascular Burden Index & $1.3 \pm 1.3$ & $1.5 \pm 1.3$ & -0.7 & n.s. \\
Beck Depression Inventory & $7.2 \pm 5.3$ & $5.9 \pm 6.6$ & 1.0 & n.s. \\
Beck Anxiety Inventory & $4.6 \pm 4.4$ & $4.2 \pm 4.8$ & 0.4 & n.s. \\
Pittsburgh Sleep Quality Index & $5.0 \pm 3.2$ & $5.7 \pm 3.7$ & -1.0 & n.s. \\
Epworth Sleepiness Scale & $7.9 \pm 4.7$ & $9.0 \pm 6.0$ & -1.0 & n.s. \\
Insomnia Severity Index & $7.0 \pm 5.2$ & $8.5 \pm 5.8$ & -1.2 & n.s. \\
Self-evaluation Questionnaire & $1.5 \pm 1.0$ & $1.7 \pm 1.0$ & -0.5 & n.s. \\
Cognitive Failure Questionnaire & $27.8 \pm 12.2$ & $30.0 \pm 13.7$ & -0.8 & n.s. \\
Right hippocampal volume $\left(\mathrm{mm}^{3}\right)$ & $3924.2 \pm 456.1$ & $4061.8 \pm 413.1$ & -1.1 & n.s. \\
Left hippocampal volume $\left(\mathrm{mm}^{3}\right)$ & $3736.2 \pm 442.3$ & $3890.9 \pm 351.0$ & -1.4 & n.s. \\
APOE (\% with $\varepsilon$ 4) & 15 & 25 & 1.36 & n.s. \\
\hline Va & & & &
\end{tabular}

Values are reported as the mean $\pm S D$, unless otherwise indicated. n..s, not significant.

\section{Materials and Methods}

\section{Subjects}

A total of 107 middle-aged and older nondemented adults (88 men and 19 women) between 55 and 84 years of age took part in this study. Seventy-nine subjects carried the wild-type Val66Val polymorphism (Val/Val carriers), while 28 subjects carried at least one copy of the Met allele (Met carriers), representing $26.2 \%$ of our study sample (Table 1 , subject characteristics). Among the Met carriers, 27 participants carried one BDNF Met allele and one participant carried the BDNF Met66Met polymorphism. This study was part of a longitudinal study on aging, cognition, and obstructive sleep apnea. Subjects were recruited from the waiting list of a sleep apnea clinic at Hôpital du Sacré-Coeur de Montréal and through the media. Twenty-four of the $79 \mathrm{Val} / \mathrm{Val}$ subjects $(30 \%)$ were recruited from the waiting list of the sleep apnea clinic versus 9 of the 28 Met carriers (32\%). No significant difference was found between the two groups in the proportion of participants recruited through the sleep apnea clinic versus through the media $\left(\chi^{2}=0.03, p=0.86\right)$. Our exclusion criteria were as follows: diagnosis of dementia based on a medical examination and according to established criteria (American Psychiatric Association, 2013); a score of $<24$ on the Mini Mental State Examination (Folstein et al., 1975); a score of $<21$ on the Montreal Cognitive Assessment (Nasreddine et al., 2005); diagnosis of a sleep disorder other than obstructive sleep apnea (e.g., narcolepsy, insomnia, rapid-eye movement (REM) sleep behavior disorder, restless leg syndrome); morbid obesity, defined as a body mass index of $>40 \mathrm{~kg} / \mathrm{m}^{2}$; a history of head injury, stroke, encephalopathy, psychiatric or neurological disease, chronic obstructive pulmonary disease, use of psychotropic medications (including drugs or alcohol abuse) that can influence sleep or cognition; use of continuous positive air pressure; and the presence of electroencephalographic anomalies suggestive of epilepsy. All participants gave written consent to participate in the study, and the hospital ethics committee approved the study. Subjects were compensated financially for participating.

\section{Procedure}

The protocol included a blood sample for genetic profiling, brain magnetic resonance imaging (MRI) acquisition to control for hippocampal volume, and an in-laboratory polysomnography (PSG) followed by neuropsychological assessment the next morning. Participants' size and weight were measured in the laboratory. Vascular risk factors were assessed using the Vascular Burden Index, a questionnaire that screens for hypertension, hypotension, hypercholesterolemia/dyslipidemia, coronary disease (angina pectoris, myocardial infarction, coronary artery bypass), transient ischemic attacks, diabetes, arrhythmias, and carotid stenosis based on previous medical observations (Villeneuve et al., 2009). All subjects filled out the following questionnaires to ensure that groups were not different in terms of mood and sleep complaints: the Beck Depression Inventory, second edition (Beck et al., 1996); the Beck Anx- 
iety Inventory (Beck and Steer, 1993); the Pittsburgh Sleep Quality Index (Buysse et al., 1989); the Epworth Sleepiness Scale (Johns, 1991); and the Insomnia Severity Index (Bastien et al., 2001). Finally, all subjects filled out questionnaires on memory complaints (Self-Evaluation Questionnaire; Van Der Linden et al., 1989; Clément et al., 2008) and subjective cognitive complaints (Cognitive Failure Questionnaire; Broadbent et al., 1982).

\section{Polysomnographic recording}

Subjects were tested with 1 night of in-laboratory PSG recording that began between 9:22 P.M. and 12:18 A.M. and ended between 5:40 and 8:36 A.M. the next morning, depending on each participant's regular sleep schedule. Sleep was recorded using a 17-channel montage (Fz, F3, F4, F7, F8, Cz, C3, C4, T7, T8, Pz, P3, P4, P7, P8, O1, and $\mathrm{O}_{2}$ ) using the international 10-20 system with a linked mastoid reference. A Grass Technologies Model 15A54 Polygraph (amplifier gain, $7.5 \mu \mathrm{V} / \mathrm{mm}$; bandpass filter, $0.3-100 \mathrm{~Hz}$ ) was used for recording, and all signals were digitized at a sampling rate of $256 \mathrm{~Hz}$ using commercial software (Harmonie, Natus). PSG included an electrooculogram, a submental electromyogram, and an electrocardiogram. Periodic leg movements were measured using an electromyogram of the bilateral anterior tibialis muscles. Thoracoabdominal strain gauges, oronasal thermistors, and oronasal cannula were used to monitor respiration, and a transcutaneous finger pulse oximeter was used to measure oxygen saturation.

\section{Neuropsychological assessment}

All neuropsychological assessments were performed in the morning following the PSG recording and started at 9:00 A.M. They included the following two episodic memory tasks: the Rey Auditory Verbal Learning Test (RAVLT; Rey, 1941); and the Logical Memory subtest of the Wechsler Memory Scale, third edition (Wechsler, 1997).

In the RAVLT, participants heard the same list of 15 common words five times. Each time, immediately after listening to the list, the subjects were asked to repeat as many words as they could recall. A second list of 15 words was then presented, followed by an immediate recall of the first list of words. A fixed battery of other cognitive tests that did not involve learning verbal material was administered for $\sim 20 \mathrm{~min}$ after the immediate recall. After this period, participants were asked to recall the first list of words they learned. In the present study, we used the total number of correctly recalled words for the five learning trials as well as the number of correctly recalled words for delayed recall.

We also used the immediate and 30 min delayed recalls of Story A, a short story presented verbally to participants, which is part of the Logical Memory subtest. We administered a modified version of the Logical Memory subtest in which Story A is presented, followed by an immediate recall and an immediate recognition task. After a 30 min period during which nonverbal tests were presented, participants were asked to recall Story A. In this modified version, Story B was not presented to reduce interference. Scores for immediate and delayed recalls were calculated separately by summing the number of correct story items reported by the participant for each recall.

Other neuropsychological tests administered were the Continuous Performance Test (Beck et al., 1956), the Digit Span subtest of the Wechsler Adult Intelligence Test, third edition (Wechsler, 1997), semantic and alphabetic fluency (Benton et al., 1994), the Trail Making Test (Reitan, 1958), the Color-Word Interference Test of the Delis-Kaplan Executive Function System (Delis et al., 2001), and the Tower of London Test (Culbertson and Zillmer, 1998). Neuropsychological tests were administered and scored blinded to the BDNF polymorphism group.

\section{MRI acquisition}

MRI acquisition was performed for $44 \mathrm{Val}$ homozygotes and $16 \mathrm{Met}$ allele carriers; other subjects were excluded from this part of the protocol due to MRI contraindications (i.e., orthopedic materials, pacemakers, or coronary stents) or claustrophobia. We used a Magnetom TRIO 3 tesla MRI scanner (Siemens Healthcare) with a three-dimensional T1weighted MPRAGE Turbo Flash multiecho system acquired with the following parameters of the Massachusetts General Hospital (Boston, MA): TR, $2530 \mathrm{~ms}$; TE, four echo times: 1.64, 3.50, 5.36, and $7.22 \mathrm{~ms}$; matrix size, $256 \times 256$; FOV , $256 \times 256$; voxel size, $1.0 \mathrm{~mm}$ isotropic; flip angle, $7^{\circ}$; and 176 sagittal orientations.

\section{Data analysis}

Sleep. Sleep stages and events were scored according to the American Academy of Sleep Medicine Manual (Iber et al., 2007) by a trained medical electrophysiology technologist (H.B.). Sleep variables were calculated for the nocturnal sleep period (i.e., time from sleep onset through last epoch of sleep). The following variables were derived: total sleep time, sleep efficiency ( percentage of time asleep during the sleep period), number of awakenings, and percentage of each sleep stage. We also analyzed the longest sleep bout during the sleep period as a measure of sleep consolidation. All sleep stages were considered in sleep bout measurement, with the exclusion of sleep bouts consisting solely of stage N1 sleep. The end of a sleep bout was determined by the occurrence of an epoch of wake. For the longest sleep bouts, 55.6\% included both NREM and REM sleep, whereas $44.4 \%$ included only NREM sleep. To derive a single measure of sleep consolidation, a principal component analysis (PCA) with a varimax rotation was performed on the following variables: sleep efficiency, number of awakenings, and longest sleep bout. These three variables were selected because they were highly correlated (absolute $r$ values ranging from 0.28 to $0.47 ; p$ values ranging from 0.002 to $<0.000001$ ). Only one significant component was obtained with PCA; it explained $58.9 \%$ of the variance and was used as the "sleep consolidation index," with a higher index representing better sleep consolidation. The component matrix showed that the three sleep variables included in the PCA highly correlated with the component extracted (absolute $r$ values ranging from 0.70 to 0.83 ).

An apneic episode was defined as a total cessation of airflow lasting $\geq 10$ s. A hypopneic episode was defined as a reduction in airflow of at least $30 \%$ from baseline lasting $\geq 10 \mathrm{~s}$ and accompanied by an oxygen desaturation of at least $3 \%$ or accompanied by an episode of arousal. The sum of the apnea and hypopnea episodes divided by the number of hours of sleep provides the apnea-hypopnea index.

Spectral analysis for NREM (stages N2 and N3) SWA $(0.6-4 \mathrm{~Hz})$ was performed on $5 \mathrm{~s}$ artifact-free sections using a fast Fourier transform (cosine tapering) and commercial software (Stellate Systems) to compute SWA $(0.6-4 \mathrm{~Hz})$ on F3 electrode. Epochs containing artifacts were considered as missing data to preserve sleep continuity. All-night NREM SWA was calculated for each subject and was averaged on 30 s epochs. Three Val/Val allele carriers and two Met allele carriers were excluded from the SWA analysis because they had significant artifacts on the F3 electrode, impeding spectral analyses.

BDNF genotyping. Genomic DNA was extracted from buffy coat using the Qiagen EZ1 DNA kit. Genotype profiling of the BDNF rs6265 (Val66Met) polymorphism was conducted through PCR followed by pyrosequencing. A PCR approach was used for amplification with the following primer pairs: forward biotin, $5^{\prime}$-GGACTCTGGAGAGCGTGAAT-3'; and reverse, 5' -CCGAACTTTCTGGTCCTCATC-3'. Genomic DNA (250-500 ng) was amplified with $10 \mathrm{pm}$ of each primer, $1 \times$ PCR buffer kit (Qiagen), $0.4 \mathrm{~mm}$ deoxynucleotide (dNTP), $1.0 \mathrm{~mm} \mathrm{MgCl}_{2}$, and $0.01 \mathrm{U}$ of Taq polymerase (Qiagen). A Biometra TProfessional Basic thermocycler was used for amplification with the following conditions for 35 cycles: $30 \mathrm{~s}$ at $95^{\circ} \mathrm{C}, 30 \mathrm{~s}$ at $61.2^{\circ} \mathrm{C}$, and $1 \mathrm{~min}$ at $72^{\circ} \mathrm{C}$. These 35 amplification cycles were preceded by a $2 \mathrm{~min}$ hot start at $95^{\circ} \mathrm{C}$ followed by a final $4 \mathrm{~min}$ extension to the last cycle at $72^{\circ} \mathrm{C}$. PCR products were visualized on a $1.2 \%$ agarose gel. The Val66Met polymorphism was subsequently determined via an established pyrosequencing protocol with oligo sequencing 5'-GCTGACACTTTCGAACA-3' (Baj et al., 2013). The analyzed sequence was as follows: CA/GTGATAGAAGAG. BDNF genotypes were validated on a subsample of 45 participants using TaqMan assay number C_11592758_10 on a Viia7 Real-Time Cycler (Life Technologies).

Apolipoprotein E $\varepsilon 4$ allele genotyping. Apolipoprotein E $\varepsilon 4$ allele (APOE4) genotyping was conducted to evaluate the proportion of individuals carrying the APOE4, a well known risk factor for Alzheimer's disease (Poirier, 2003). This variable contributed to ensure that our two groups were equivalent in the proportion of individuals susceptible to present preclinical dementia. Genomic DNA was extracted from buffy coat using the Qiagen EZ1 DNA Kit. Genotype profiling of ApoE 112/158 
single nucleotide polymorphisms (which determine the E2, E3, and E4 isoforms) was performed through PCR followed by pyrosequencing. A PCR approach was used for amplification with the following primer pairs: ApoE 112: forward, 5'-ACGGCTGTCCAAGGAGCTG-3', and reverse, biotin 5'-CACCTCGCCGCGGTACTG-3'; and ApoE 158: forward, 5'-CTCCGCGATGCCGATGAC-3', and reverse, biotin 5' CCCCGGCCTGGTACACTG-3'. Genomic DNA (250-500 ng) was amplified with 20 pM each primer, $1 \times$ PCR buffer kit (Qiagen), $0.4 \mathrm{~mm}$ dNTP, $1.0 \mathrm{mM} \mathrm{MgCl}_{2}$, DMSO, and $0.01 \mathrm{U}$ of Qiagen Taq polymerase. A Biometra TProfessional Basic Thermocycler was used for amplification with the following conditions for 35 cycles: $30 \mathrm{~s}$ at $95^{\circ} \mathrm{C}, 30 \mathrm{~s}$ at $58.6^{\circ} \mathrm{C}$, or $58.1^{\circ} \mathrm{C}$ for ApoE 112 or 158 respectively, and $1 \mathrm{~min}$ at $72^{\circ} \mathrm{C}$. These 35 amplification cycles were preceded by a $2 \mathrm{~min}$ hot start at $95^{\circ} \mathrm{C}$ and were followed by a final 4 min extension to the last cycle at $72^{\circ} \mathrm{C}$. PCR products were visualized on a $1.2 \%$ agarose gel. The polymorphisms were subsequently determined via an established pyrosequencing protocol with oligo sequencing for ApoE112 (5'-CGGACATGGAGGACG-3') and ApoE 158 (5'-CGATGACCTGCAGAAG-3'). The analyzed sequence was as follows: TGT/CGCGGCCGCCT for ApoE112 and T/CGCCTG GCAG for ApoE158.

\section{Hippocampal volume measurement}

Hippocampal volume was measured as a control procedure to ensure that our two groups were equivalent. Using FreeSurfer Image Analysis Suite version 5.3.0. (Laboratory for Computational Neuroimaging, Center for Biomedical Imaging, Charlestown, MA), a volumetric segmentation of all subcortical structures was performed on individual T1weighted images. This process has been extensively described in previous studies (Fischl et al., 2002, 2004), and the FreeSurfer image analysis suite is documented and available on-line. Briefly, this volume-based subcortical stream consists of automated steps that include the removal of nonbrain tissue, an automated Talairach transformation, and a volumetric segmentation and labeling of subcortical structures. All the individual processed images were visually inspected to assess the quality of the segmentation, and left and right hippocampal volumes were extracted. Hippocampal volume was measured to describe the BDNF polymorphism groups.

\section{Statistical analyses}

Statistical analyses were conducted using SPSS for Mac version 20.0 (SPSS Science). Differences between BDNF polymorphism groups on demographic, neuropsychological, neuroimaging, and sleep variables were measured using Student's $t$ tests or $\chi^{2}$ tests, depending on the type of variable. The hypothesis that the BDNF polymorphism would interact with all-night NREM SWA $(0.6-4.0 \mathrm{~Hz})$ and the sleep consolidation index to predict memory performance the next morning was tested using eight hierarchical linear regressions. More specifically, we tested whether $B D N F$ polymorphism is a moderating variable that affects the direction and/or the strength of the relation between independent variables (i.e., NREM SWA and sleep consolidation) and dependent variables (i.e., performance in the memory tests; Baron and Kenny, 1986). Four memory variables were used: for RAVLT, (1) the number of correctly recalled words in learning trials and (2) delayed recall; and for the Logical Memory subtest, Story A (3) immediate recall and (4) delayed recall. Control variables included in the hierarchical linear regressions were age, sex, number of years of education, and time with oxygen saturation $<90 \%$ during sleep. They were selected because of their possible association with performance on episodic memory tasks (Rönnlund et al., 2005; Morrell and Twigg, 2006). Control variables (age, sex, education, and oxygen desaturation during sleep) and independent variables were all mean centered for regression analyses. Control variables were entered in the analysis in step 1. BDNF polymorphism and sleep variables were entered in step 2, while the interaction between BDNF polymorphism and sleep variables was entered in step 3. Four hierarchical linear regressions were performed for each sleep variable, namely, NREM SWA and the sleep consolidation index. Correlations among the continuous predictor variables of the study (age, education, time with oxygen saturation $<90 \%$, NREM SWA power, and sleep consolidation index) were examined and showed no to moderate correlations, ranging from $r=-0.02$,
Table 2. Sleep variables for Val/Val and Met carriers

\begin{tabular}{lccrl}
\hline Variables & $\begin{array}{c}\text { Val/Val carriers } \\
(n=79)\end{array}$ & $\begin{array}{l}\text { Met carriers } \\
(n=28)\end{array}$ & $\begin{array}{l}l \\
\text { values }\end{array}$ & $\begin{array}{l}p \\
\text { values }\end{array}$ \\
\hline Stage N1 sleep (min) & $81.4 \pm 33.7$ & $82.1 \pm 41.7$ & -0.1 & n.s. \\
Stage N2 sleep (min) & $196.2 \pm 53.1$ & $192.8 \pm 64.2$ & 0.3 & n.s. \\
Stage N3 sleep (min) & $23.0 \pm 26.2$ & $31.6 \pm 29.7$ & -1.4 & n.s. \\
REM sleep (min) & $53.5 \pm 24.3$ & $49.9 \pm 23.0$ & 0.7 & n.s. \\
Total sleep time (min) & $354.1 \pm 66.6$ & $356.3 \pm 77.5$ & -0.2 & n.s. \\
Number of awakenings & $47.9 \pm 20.1$ & $45.3 \pm 26.0$ & 0.6 & n.s. \\
Sleep efficiency (\%) & $76.8 \pm 12.1$ & $76.9 \pm 13.0$ & -0.02 & n.s. \\
Longest sleep bout (min) & $55.8 \pm 18.1$ & $56.6 \pm 20.9$ & -0.2 & n.s. \\
Slow-wave activity power $\left(\mu \mathrm{V}^{2} / 30 \mathrm{~s}\right)$ & $222.9 \pm 112.1$ & $260.0 \pm 158.1$ & -1.3 & n.s. \\
Apnea- hypopnea index & $20.3 \pm 17.1$ & $18.9 \pm 15.1$ & 0.4 & n.s. \\
Time with oxygen saturation $<90 \%$ (min) & $7.1 \pm 15.2$ & $13.3 \pm 22.7$ & -1.6 & n.s. \\
\hline
\end{tabular}

Values are reported as the mean $\pm S D$. n.s., not significant.

Table 3. Neuropsychological results for Val/Val and Met carriers

\begin{tabular}{lclrl}
\hline Variables & $\begin{array}{l}\text { Val/Val carriers } \\
(n=79)\end{array}$ & $\begin{array}{l}\text { Met carriers } \\
(n=28)\end{array}$ & $\begin{array}{l}t \\
\text { values }\end{array}$ & $\begin{array}{l}p \\
\text { values }\end{array}$ \\
\hline MoCA & $27.8 \pm 2.1$ & $27.0 \pm 2.2$ & 1.7 & n.s. \\
MMSE & $28.7 \pm 1.4$ & $29.0 \pm 0.9$ & -1.3 & n.s. \\
RAVLT & & & & \\
$\quad$ Learning trials (no. of words) & $49.1 \pm 10.2$ & $47.1 \pm 9.1$ & 0.9 & n.s. \\
$\quad \begin{array}{l}\text { Delayed recall (no. of words) } \\
\text { Logical Memory subtest of WMS-III }\end{array}$ & $9.5 \pm 3.3$ & $9.6 \pm 3.1$ & 0.02 & n.s. \\
$\quad$ Story A immediate recall & $14.3 \pm 3.8$ & $14.7 \pm 3.6$ & -0.5 & n.s. \\
$\quad$ Story A delayed recall & $16.6 \pm 3.5$ & $17.6 \pm 2.4$ & -1.4 & n.s. \\
\hline
\end{tabular}

Values are reported as the mean \pm SD. MoCA, Montreal Cognitive Assessment; MMSE, Mini Mental State Examination; WMS-III, Wechsler Memory Scale, third edition; n.S., not significant.

$p=$ n.s. to $r=-0.24, p<0.05$. These low $r$ values indicate that multicollinearity was unlikely. The Bonferroni correction was applied for these eight models, and significance was set at $p<0.00625$. Outliers were defined by standardized residuals ( $z$ scores) of $>3.29$ or $<3.29$ (Tabachnick and Fidell, 2001), and, therefore, data from one Val/Val individual were excluded from one hierarchical regression. Significant interactions were tested using procedures previously described (Aiken and West, 1991), and fitted regression lines were plotted for each level of the dichotomous moderator (i.e., BDNF polymorphism) with an adjusted individual data point.

Control analyses were performed using hierarchical linear regressions with total sleep time as an independent variable to verify whether BDNF polymorphism moderates the association between sleep duration and next-morning learning ability. To verify whether the moderating effect of $B D N F$ polymorphism on sleep was specific to declarative episodic memory, we performed additional hierarchical linear regression analyses on the other neuropsychological tests administered.

\section{Results}

No effect of $B D N F$ polymorphism on demographic, neuroimaging, sleep, and neuropsychological variables

No between-group differences were observed for age, sex ratio, education level, body mass index, hippocampal volume, proportion of subjects carrying the APOE4, and vascular burden index (Table 1$)$. Our sample consisted mainly of men $(78.4 \%$ of Val/Val carriers and $75 \%$ of Met carriers). Using questionnaires, we found no group difference with respect to depression, anxiety, sleep quality, and memory and cognitive complaints. Groups were not different in terms of PSG variables, including respiratory variables (Table 2). Finally, we found no significant group difference on cognitive screening tests, on the episodic memory variables used in the study (Table 3), and on other neuropsychological variables (i.e., Continuous Performance Test, Digit Span, verbal fluency, Color-Word Interference, and Tower of London). 
Table 4. Hierarchical regression analyses with BDNF polymorphism and sleep consolidation index predicting scores on RAVLT and Logical Memory immediate and delayed recalls

\begin{tabular}{|c|c|c|c|c|c|c|}
\hline \multirow[b]{2}{*}{ Predictors } & \multicolumn{3}{|l|}{ RAVLT } & \multicolumn{3}{|c|}{ Logical Memory } \\
\hline & $\beta$ & $R^{2}$ & $R^{2}$ change & $\beta$ & $R^{2}$ & $R^{2}$ change \\
\hline \multicolumn{7}{|l|}{ Learning trials (RAVLT)/immediate recall (Logical Memory) } \\
\hline Step 1 & & $19.0 \% * *$ & & & $11.4 \% *$ & \\
\hline Age & -0.162 & & & -0.064 & & \\
\hline Sex & $0.363^{* *}$ & & & $0.237^{*}$ & & \\
\hline Education & $0.234^{*}$ & & & $0.266^{*}$ & & \\
\hline Oxygen saturation $<90 \%$ during sleep & 0.029 & & & 0.071 & & \\
\hline Step 2 & & $20.7 \% * *$ & $1.7 \%$ & & $14.4 \% *$ & $1.7 \%$ \\
\hline BDNF polymorphism group & -0.084 & & & 0.064 & & \\
\hline Sleep consolidation index & 0.113 & & & 0.167 & & \\
\hline Step 3 & & $27.0 \% * *$ & $6.3 \% * *$ & & $27.6 \% * * *$ & $18.1 \% * * *$ \\
\hline BDNF polymorphism group $\times$ sleep consolidation index & $-0.255^{* *}$ & & & $-0.371^{* * *}$ & & \\
\hline \multicolumn{7}{|l|}{ Delayed recalls } \\
\hline Step 1 & & $14.6 \% * *$ & & & $5.5 \%$ & \\
\hline Age & -0.079 & & & -0.030 & & \\
\hline Sex & $0.312^{* *}$ & & & 0.125 & & \\
\hline Education & $0.242^{*}$ & & & $0.207^{*}$ & & \\
\hline 0xygen saturation $<90 \%$ during sleep & 0.131 & & & 0.099 & & \\
\hline Step 2 & & $15.9 \% *$ & $1.3 \%$ & & $10.3 \%$ & $4.7 \%$ \\
\hline BDNF polymorphism group & -0.002 & & & 0.134 & & \\
\hline Sleep consolidation index & 0.121 & & & 0.180 & & \\
\hline Step 3 & & $22.3 \% * *$ & $6.4 \% * *$ & & $16.6 \% *$ & $6.4 \% *$ \\
\hline BDNF polymorphism group $\times$ sleep consolidation index & $-0.258^{* *}$ & & & $-0.257^{*}$ & & \\
\hline
\end{tabular}

${ }^{*} p<0.05$ (trend for significance), ${ }^{* *} p<0.00625$ ( $p$ level threshold when Bonferroni correction was applied), ${ }^{* * *} p<0.0001$.

Moderating effect of $B D N F$ polymorphism on the association between sleep consolidation and memory

Hierarchical regression models showed that sleep interacts with $B D N F$ polymorphism on both verbal memory tests (Table 4). In fact, $B D N F$ polymorphism was found to have a significant moderating effect on the association between the sleep consolidation index and three of the four memory variables tested (RAVLT learning trials: $\beta=-0.255, p<0.006$; RAVLT delayed recall: $\beta=-0.258, p<0.006$; Logical Memory immediate recall: $\beta=$ $-0.371, p<0.006$; and a trend for Logical Memory delayed recall: $\beta=-0.257, p=0.0074$, which was only a trend for significance when the Bonferroni correction was applied). These moderating effects explained from $6.3 \%$ to $18.1 \%$ of the variance on the RAVLT and the Logical Memory subtest. A decomposition of significant interactions showed that, among Val/Val carriers, a higher sleep consolidation index was associated with better memory performance (RAVLT learning trials: $\beta=0.290, p=0.01$; RAVLT delayed recall: $\beta=0.306, p=0.006$; Logical Memory immediate recall: $\beta=0.434, p=0.0001$; Logical Memory delayed recall: $\beta=0.315, p=0.01$ ) and accounted for $7.4 \%$ to $16.5 \%$ of the variance. The significant interaction stemmed from the fact that these positive associations between sleep consolidation and memory performance were not observed among Met carriers. In fact, better sleep consolidation was associated with poorer memory performance on Logical Memory immediate recall in Met carriers $(\beta=-0.585, p=0.005$; Fig. $1 A)$ and explained $28.7 \%$ of the variance. Trends for negative associations were also found between sleep consolidation and performance on RAVLT learning trials $(\beta=-0.352, p=0.07$; Fig. $1 B)$ and Logical Memory delayed recall $(\beta=-0.392, p=0.056)$.

\section{No moderating effect of BDNF polymorphism on NREM SWA and total sleep time}

NREM SWA was not associated with memory performance the next morning. Moreover, no significant interaction between $B D N F$ polymorphism and NREM SWA power was observed. Analyses were conducted with total sleep time as an independent variable; no significant interaction with $B D N F$ polymorphism was found to predict memory performance, although trends for significant effects were observed for RAVLT delayed recall $(\beta=$ $0.216, p=0.03)$ and Logical memory immediate recall $(\beta=$ $0.174, p=0.08)$. Independent of BDNF polymorphism, longer sleep duration was associated with better performance on both RAVLT and Logical Memory immediate recalls ( $\beta$-values of 0.233 and 0.249 , respectively; $p=0.01$ ).

\section{Cognitive domains other than memory}

Supplementary analyses with other neuropsychological tests revealed that the $B D N F$ Met allele selectively compromises the association between sleep and verbal memory with little effect on tasks involving the prefrontal cortex and no impact on other cognitive domains. Although trends for sleep (NREM SWA or sleep consolidation index) by BDNF polymorphism interaction were found for Digit Span, Trail Making Test part $\mathrm{B}$, and Color-Word Interference (time to complete Condition 3 ; $p$ values $<0.05$, but $>0.01$ ), no significant interaction persisted when a correction for multiple testing was applied.

\section{Discussion}

Sleep consolidation and NREM SWA have been identified as having a crucial role in learning (Tartar et al., 2006; Yoo et al., 2007; Van Der Werf et al., 2009; Rolls et al., 2011; Wallace et al., 2015). In the present study, we observed that BDNF Val/ Met polymorphism moderates the association between memory and the sleep consolidation index, a variable integrating the number of awakenings, sleep efficiency, and the longest sleep bout. More specifically, we found that a night of consolidated sleep was associated with better learning abilities the next morning among Val/Val carriers. Our results confirm previous animal models showing the specific effect of sleep fragmentation on memory (Tartar et al., 2006; Rolls et al., 2011; Wallace et al., 2015). However, this positive sleep-memory association was not observed among Met carriers. These results support the hypothesis that reduced activity- 

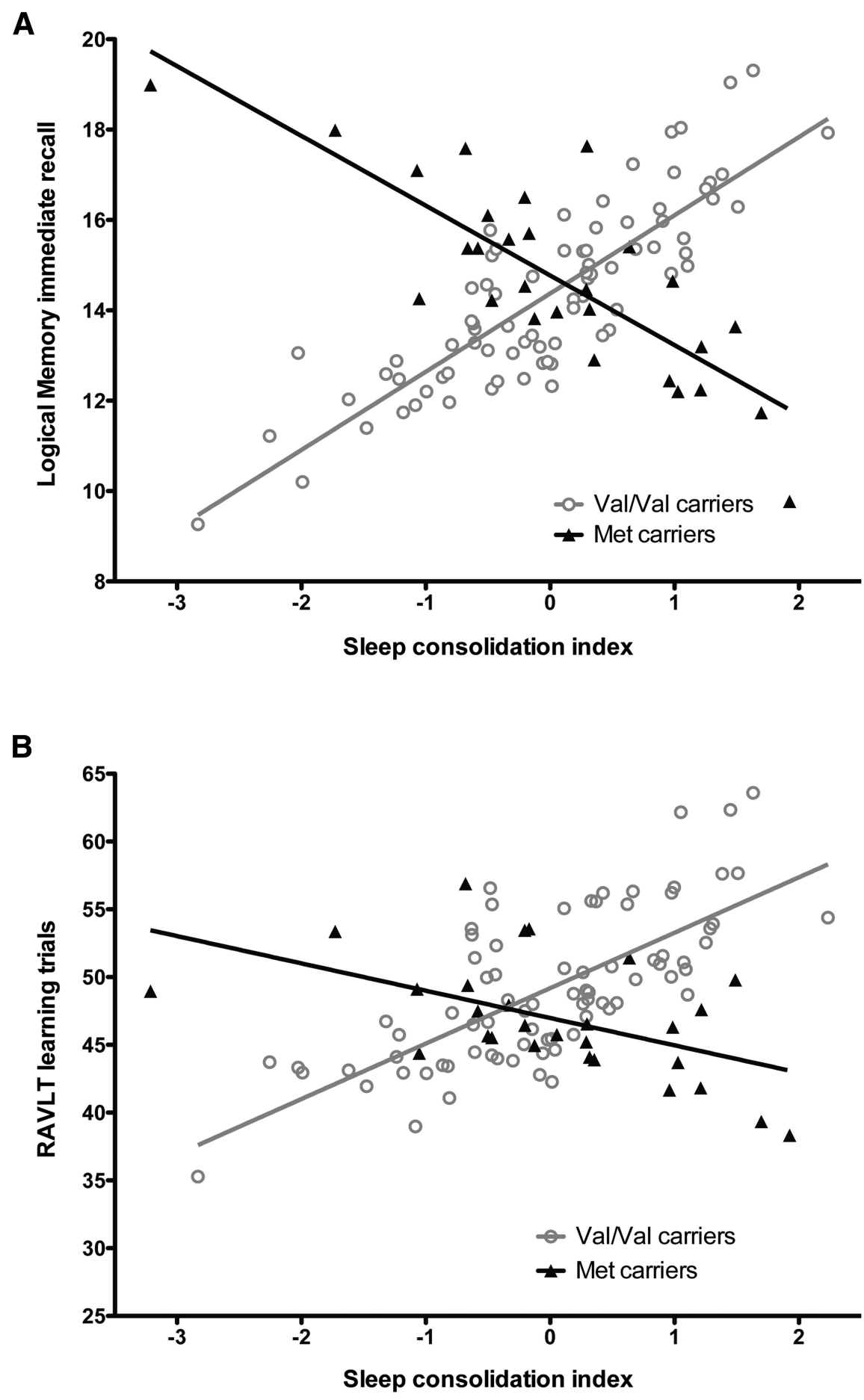

Figure 1. Sleep consolidation and memory performance for Val/Val and Met carriers. $A, B$, Fitted regression lines for Logical Memory: Story A immediate recall $(\boldsymbol{A})$ and Rey Auditory Verbal Learning Test learning trials $(\boldsymbol{B})$ according to sleep consolidation index in $\mathrm{Val} / \mathrm{Val}$ (open gray circles) and Met carriers (black triangles). A higher sleep consolidation index represents a more consolidated sleep. Individual data points represent values adjusted for control variables (age, sex, education, time with oxygen saturation $<90 \%$ during sleep).

dependent secretion of BDNF impairs the benefits of sleep on synaptic plasticity and next-day memory.

Lower sleep consolidation is associated with better learning among Met carriers

Interestingly, for Logical Memory immediate recall in Met carriers, we observed that lower sleep consolidation was associated with bet- ter learning. This negative association was also found for the three other memory variables in Met carriers, but failed to reach significance ( $p$ value range from 0.056 to 0.15 ). This raises the question as to whether Met carriers see a benefit from increased sleep fragmentation (i.e., the number of awakenings during the night) in the form of improvements in their next-day memory performance. One explanation may be the use of an efficient compensatory cognitive strategy among Met carriers who experienced a poor night of sleep. In a rodent study, it was observed that sleep-deprived mice avoided the use of a hippocampusdependent strategy to perform a memory task and instead used a striatum-dependent strategy (Hagewoud et al., 2010). In parallel, previous studies in elderly subjects have shown that Met carriers have more efficient or preserved frontostriatal functions than $\mathrm{Val} /$ Val individuals (Gajewski et al., 2012; Getzmann et al., 2013). Although declarative memory was believed to mostly depend on hippocampus integrity, there is now compelling evidence that the striatum, along with the prefrontal cortex, may be involved (Scimeca and Badre, 2012). Our findings thus raise the intriguing possibility that poor sleep consolidation may have promoted the use of a striatum-dependent memory strategy that is potentially advantageous to Met carriers, who may have more efficient or better preserved frontostriatal functions than $\mathrm{Val} / \mathrm{Val}$ individuals.

Another explanation might reside in a possible enhancement of BDNF expression during nighttime wakefulness. Indeed, BDNF mRNA expression has been reported to increase with acute prolonged wakefulness in rodents (Huber et al., 2007; El Helou et al., 2013). This increased BDNF expression may benefit next-day memory in the Met carriers who experienced frequent awakenings during their night of sleep. The negative association between sleep consolidation and memory was not observed among Val homozygotes, possibly because they already have abundant levels of BDNF. According to this hypothesis, a consolidated sleep will have more benefits in improving memory in Val/Val carriers, compared with Met allele carriers, because of their abundant levels of BDNF.
BDNF polymorphism is not a moderator of NREM SWA and memory association in middle-aged and older individuals

Surprisingly, there was a lack of interaction between BDNF polymorphism and NREM SWA, suggesting that SWA plays the same role in next-day learning ability among Val/Val and Met carriers. However, we cannot exclude the idea that the lack of moderating effect may stem from our sample, which was made up of individ- 
uals between 55 and 84 years of age, a segment of the population known to experience less slow-wave sleep than younger adults (Carrier et al., 2001). In parallel, it was reported that $\mathrm{Val} / \mathrm{Val}$ carriers had more slow-wave sleep and more SWA than Met carriers (Bachmann et al., 2012), but another study failed to observe a group difference in their sleep characteristics (Mascetti et al., 2013). In rodents, BDNF injection over the hippocampus was also shown to increase SWA (Faraguna et al., 2008). However, in the present study, we found that BDNF polymorphism had no effect on SWA. Again, this lack of a BDNF polymorphism group difference may be attributable to the fact that our participants were middle-aged or older adults.

\section{The moderating effect of $B D N F$ polymorphism is stronger for memory than for other cognitive functions}

The moderating role of BDNF polymorphism in sleep consolidation was specific to episodic memory tasks. Although trends for significant moderating effects were found for tests mostly involving the prefrontal cortex, no significant interaction was observed for the other cognitive domains, reflecting that sleep by $B D N F$ polymorphism interaction is more salient for hippocampusdependent tasks than for other cognitive tasks. Concordant with this observation, a previous study of sleep deprivation failed to find a sleep by BDNF polymorphism interaction to explain working memory performance in young adults (Bachmann et al., 2012). Another study showed that Val/Val carriers have a greater increase in their performance in memorizing neutral faces learned before sleep than Met carriers, demonstrating that BDNF polymorphism interacts with sleep to explain overnight memory consolidation for a hippocampus-dependent task (Mascetti et al., 2013).

\section{Sleep quality is a key element to understanding the effect of $B D N F$ polymorphism on episodic memory}

Our results explain some of the inconsistencies observed regarding the better performance of $\mathrm{Val} / \mathrm{Val}$ carriers over Met carriers for episodic memory (Mandelman and Grigorenko, 2012). In fact, we showed that the enhanced performance of Val/Val carriers was observed only when subjects experienced a night of well consolidated sleep before learning. Thus, uncontrolled sleep quality preceding memory testing in previous studies may have led to heterogeneous results for the effect of BDNF polymorphism on episodic memory. The significant interaction between sleep consolidation and BDNF polymorphism may be an essential missing variable, particularly in middle-aged and older populations.

\section{Strengths and limitations of the study}

The strengths and limitations of this study relate mainly to the characteristics of our sample. The BDNF polymorphism groups were not different for all demographic variables (including education), subjective cognitive complaints, vascular burden, neuropsychological performance, hippocampal volume, and APOE4 genotype. We can therefore assume that the groups were similar with respect to the proportion of individuals with preclinical dementia. Nonetheless, we cannot exclude the fact that some individuals might have been in a presymptomatic stage of dementia, and biomarkers such as positron emission tomography with the Pittsburgh Compound-B ligand would have been of great interest in our sample (Jack et al., 2016). Whether the neural consequences of chronic sleep fragmentation predict a further cognitive decline among older individuals is an interesting question that needs to be investigated with longitudinal studies that carefully track sleep history.

Our sample consisted mainly of men. Although sex was added as a control variable in our statistics, we should be cautious in extending the present findings to women. Another factor to consider is that $31 \%$ of our subjects were recruited from the waiting list for a sleep apnea clinic, which means our sample included a higher proportion of individuals with sleep apnea (47.7\% of our sample) than the $17 \%$ expected prevalence for men $50-70$ years of age (Peppard et al., 2013). To control for the effect of obstructive sleep apnea, we included time spent with oxygen saturation $<90 \%$ during sleep as a control variable in the regression analyses. Another limitation is the sample size of the Met carrier group, which was smaller than the $\mathrm{Val} / \mathrm{Val}$ group. This lower proportion was nevertheless expected, given the frequency of the Met allele in the population (Egan et al., 2003). However, in the case of significant interactions, we reported $R^{2}$ changes, which represent effect size and allow us to compare the associations observed for each group. Finally, the results of this study must be replicated with an independent sample, and a comparison of young versus older adults is the next step to understanding how BDNF polymorphism moderates the sleep-memory association.

\section{Conclusions}

Our work advances the field by revealing new evidence of genetic heterogeneity in how sleep consolidation contributes to learning ability. It reveals a complex, intricate relationship among sleep, $B D N F$ polymorphism, and learning that merits further attention. This study confirms that better sleep consolidation is associated with better next-day learning in $\mathrm{Val} / \mathrm{Val}$ individuals, who account for most of the population. However, our results also stress the importance of considering BDNF polymorphism when studying how sleep affects cognition, since the positive effect of sleep consolidation on memory was not found in Met carriers. Understanding the effect of the BDNF Met allele on specific components of a simple form of learning provides insight into the consequences of specific sleep disorders, particularly medical or neurodegenerative conditions that cause sleep fragmentation and memory dysfunction, such as obstructive sleep apnea (Gagnon et al., 2014) and Alzheimer's disease (Widner et al., 2000). It is worth looking into whether sleep disorders have the same long-term detrimental effects on brain health and cognition in BDNF Val/Val and Met carriers.

\section{References}

Aiken LS, West SG (1991) Multiple regression: testing and interpreting interactions. Newbury Park, CA: Sage.

American Psychiatric Association (2013) Diagnostic and statistical manual of mental disorders, Ed 5. Arlington, VA: American Psychiatric Association.

Bachmann V, Klein C, Bodenmann S, Schäfer N, Berger W, Brugger P, Landolt HP (2012) The BDNF Val66Met polymorphism modulates sleep intensity: EEG frequency-and state-specificity. Sleep 35:335-344. Medline

Baj G, Carlino D, Gardossi L, Tongiorgi E (2013) Toward a unified biological hypothesis for the BDNF Val66Met-associated memory deficits in humans: a model of impaired dendritic mRNA trafficking. Front Neurosci 7:188. CrossRef Medline

Baron RM, Kenny DA (1986) The moderator-mediator variable distinction in social psychological research: conceptual, strategic, and statistical considerations. J Pers Soc Psychol 51:1173-1182. CrossRef Medline

Bastien CH, Vallières A, Morin CM (2001) Validation of the Insomnia Severity Index as an outcome measure for insomnia research. Sleep Med 2:297-307. CrossRef Medline

Beck AT, Steer RA (1993) Beck anxiety manual. San Antonio, TX: Psychological Corporation.

Beck AT, Steer RA, Brown GK (1996) Manual for the Beck depression inventory-II. San Antonio, TX: Psychological Corporation. 
Beck LH, Bransome ED Jr, Mirsky AF, Rosvold HE, Sarason I (1956) A continuous performance test of brain damage. J Consult Psychol 20: 343-350. CrossRef Medline

Benton AL, Hamsher K, Sivan AB (1994) Multilingual aphasia examination, Ed 3. Iowa City, IA.: AJA Associates.

Broadbent DE, Cooper PF, FitzGerald P, Parkes KR (1982) The Cognitive Failures Questionnaire (CFQ) and its correlates. Br J Clin Psychol 21: 1-16. CrossRef Medline

Buysse DJ, Reynolds CF 3rd, Monk TH, Berman SR, Kupfer DJ (1989) The Pittsburgh Sleep Quality Index: a new instrument for psychiatric practice and research. Psychiatry Res 28:193-213. CrossRef Medline

Carrier J, Land S, Buysse DJ, Kupfer DJ, Monk TH (2001) The effects of age and gender on sleep EEG power spectral density in the middle years of life (ages 20-60 years old). Psychophysiology 38:232-242. CrossRef Medline

Clément F, Belleville S, Gauthier S (2008) Cognitive complaint in mild cognitive impairment and Alzheimer's disease. J Int Neuropsychol Soc 14: 222-232. CrossRef Medline

Culbertson WC, Zillmer EA (1998) The Tower of London(DX): a standardized approach to assessing executive functioning in children. Arch Clin Neuropsychol 13:285-301. CrossRef Medline

Delis DC, Kaplan E, Kramer JH (2001) Delis-Kaplan Executive Function System (D-KEFS). San Antonio, TX: Psychological Corporation.

Diekelmann S, Born J (2010) The memory function of sleep. Nat Rev Neurosci 11:114-126. CrossRef Medline

Drummond SP, Brown GG, Gillin JC, Stricker JL, Wong EC, Buxton RB (2000) Altered brain response to verbal learning following sleep deprivation. Nature 403:655-657. CrossRef Medline

Egan MF, Kojima M, Callicott JH, Goldberg TE, Kolachana BS, Bertolino A, Zaitsev E, Gold B, Goldman D, Dean M, Lu B, Weinberger DR (2003) The BDNF val66met polymorphism affects activity-dependent secretion of BDNF and human memory and hippocampal function. Cell 112: 257-269. CrossRef Medline

El Helou J, Bélanger-Nelson E, Freyburger M, Dorsaz S, Curie T, La Spada F, Gaudreault PO, Beaumont É, Pouliot P, Lesage F, Frank MG, Franken P, Mongrain V (2013) Neuroligin-1 links neuronal activity to sleep-wake regulation. Proc Natl Acad Sci U S A 110:9974-9979. CrossRef Medline

Faraguna U, Vyazovskiy VV, Nelson AB, Tononi G, Cirelli C (2008) A causal role for brain-derived neurotrophic factor in the homeostatic regulation of sleep. J Neurosci 28:4088-4095. CrossRef Medline

Fischl B, Salat DH, Busa E, Albert M, Dieterich M, Haselgrove C, van der Kouwe A, Killiany R, Kennedy D, Klaveness S, Montillo A, Makris N, Rosen B, Dale AM (2002) Whole brain segmentation: automated labeling of neuroanatomical structures in the human brain. Neuron 33: 341-355. CrossRef Medline

Fischl B, Salat DH, van der Kouwe AJ, Makris N, Segonne F, Quinn BT, Dale AM (2004) Sequence-independent segmentation of magnetic resonance images. Neuroimage 23 [Suppl 1]:S69-S84. CrossRef Medline

Folstein MF, Folstein SE, McHugh PR (1975) "Mini-mental state": A practical method for grading the cognitive state of patients for the clinician. J Psychiatr Res 12:189-198. CrossRef Medline

Gagnon K, Baril AA, Gagnon JF, Fortin M, Decary A, Lafond C, Desautels A, Montplaisir J, Gosselin N (2014) Cognitive impairment in obstructive sleep apnea. Pathol Biol (Paris) 62:233-240. CrossRef Medline

Gajewski PD, Hengstler JG, Golka K, Falkenstein M, Beste C (2012) The Met-genotype of the BDNF Val66Met polymorphism is associated with reduced Stroop interference in elderly. Neuropsychologia 50:3554-3563. CrossRef Medline

Getzmann S, Gajewski PD, Hengstler JG, Falkenstein M, Beste C (2013) BDNF Val66Met polymorphism and goal-directed behavior in healthy elderly-evidence from auditory distraction. Neuroimage 64:290-298. CrossRef Medline

Hagewoud R, Havekes R, Tiba PA, Novati A, Hogenelst K, Weinreder P, Van der Zee EA, Meerlo P (2010) Coping with sleep deprivation: shifts in regional brain activity and learning strategy. Sleep 33:1465-1473. Medline

Huber R, Tononi G, Cirelli C (2007) Exploratory behavior, cortical BDNF expression, and sleep homeostasis. Sleep 30:129-139. Medline

Iber C, Ancoli-Israel S, Chesson A, Quan SF (2007) The AASM manual for the scoring of sleep and associated events: rules, terminology, and technical specification. Westchester, IL: American Academy of Sleep Medicine.

Jack CR Jr, Therneau TM, Wiste HJ, Weigand SD, Knopman DS, Lowe VJ, Mielke MM, Vemuri P, Roberts RO, Machulda MM, Senjem ML, Gunter JL, Rocca WA, Petersen RC (2016) Transition rates between amyloid and neurodegeneration biomarker states and to dementia: a population-based, longitudinal cohort study. Lancet Neurol 15:56-64. CrossRef Medline

Johns MW (1991) A new method for measuring daytime sleepiness: the Epworth sleepiness scale. Sleep 14:540-545. Medline

Kang H, Schuman EM (1995) Long-lasting neurotrophin-induced enhancement of synaptic transmission in the adult hippocampus. Science 267:1658-1662. CrossRef Medline

Kennedy KM, Reese ED, Horn MM, Sizemore AN, Unni AK, Meerbrey ME, Kalich AG Jr, Rodrigue KM (2015) BDNF val66met polymorphism affects aging of multiple types of memory. Brain Res 1612:104-117. CrossRef Medline

Korte M, Carroll P, Wolf E, Brem G, Thoenen H, Bonhoeffer T (1995) Hippocampal long-term potentiation is impaired in mice lacking brainderived neurotrophic factor. Proc Natl Acad Sci U S A 92:8856-8860. CrossRef Medline

Lafortune M, Gagnon JF, Martin N, Latreille V, Dubé J, Bouchard M, Bastien C, Carrier J (2014) Sleep spindles and rapid eye movement sleep as predictors of next morning cognitive performance in healthy middle-aged and older participants. J Sleep Res 23:159-167. CrossRef Medline

Mandelman SD, Grigorenko EL (2012) BDNF Val66Met and cognition: all, none, or some? A meta-analysis of the genetic association. Genes Brain Behav 11:127-136. CrossRef Medline

Mander BA, Santhanam S, Saletin JM, Walker MP (2011) Wake deterioration and sleep restoration of human learning. Curr Biol 21:R183-R184. CrossRef Medline

Mascetti L, Foret A, Schrouff J, Muto V, Dideberg V, Balteau E, Degueldre C, Phillips C, Luxen A, Collette F, Bours V, Maquet P (2013) Concurrent synaptic and systems memory consolidation during sleep. J Neurosci 33: 10182-10190. CrossRef Medline

Morrell MJ, Twigg G (2006) Neural consequences of sleep disordered breathing: the role of intermittent hypoxia. Adv Exp Med Biol 588:75-88. CrossRef Medline

Nasreddine ZS, Phillips NA, Bédirian V, Charbonneau S, Whitehead V, Collin I, Cummings JL, Chertkow H (2005) The Montreal Cognitive Assessment, MoCA: a brief screening tool for mild cognitive impairment. J Am Geriatr Soc 53:695-699. CrossRef Medline

Peigneux P, Laureys S, Fuchs S, Collette F, Perrin F, Reggers J, Phillips C, Degueldre C, Del Fiore G, Aerts J, Luxen A, Maquet P (2004) Are spatial memories strengthened in the human hippocampus during slow wave sleep? Neuron 44:535-545. CrossRef Medline

Peppard PE, Young T, Barnet JH, Palta M, Hagen EW, Hla KM (2013) Increased prevalence of sleep-disordered breathing in adults. Am J Epidemiol 177:1006-1014. CrossRef Medline

Poirier J (2003) Apolipoprotein E and cholesterol metabolism in the pathogenesis and treatment of Alzheimer's disease. Trends Mol Med 9:94-101. CrossRef Medline

Reitan RM (1958) Validity of the trail making test as an indicator of organic brain damage. Percept Mot Skills 8:271-276. CrossRef

Rey A (1941) L'examen psychologique dans les cas d'encéphalopathie traumatique. Arch Psychol 28:286.

Rolls A, Colas D, Adamantidis A, Carter M, Lanre-Amos T, Heller HC, de Lecea L (2011) Optogenetic disruption of sleep continuity impairs memory consolidation. Proc Natl Acad Sci U S A 108:13305-13310. CrossRef Medline

Rönnlund M, Nyberg L, Bäckman L, Nilsson LG (2005) Stability, growth, and decline in adult life span development of declarative memory: crosssectional and longitudinal data from a population-based study. Psychol Aging 20:3-18. CrossRef Medline

Scimeca JM, Badre D (2012) Striatal contributions to declarative memory retrieval. Neuron 75:380-392. CrossRef Medline

Tabachnick BG, Fidell LS (2001) Using multivariate statistics, Ed 4. Boston: Allyn and Bacon.

Tartar JL, Ward CP, McKenna JT, Thakkar M, Arrigoni E, McCarley RW, Brown RE, Strecker RE (2006) Hippocampal synaptic plasticity and spatial learning are impaired in a rat model of sleep fragmentation. Eur J Neurosci 23:2739-2748. CrossRef Medline

Tononi G, Cirelli C (2014) Sleep and the price of plasticity: from synaptic and cellular homeostasis to memory consolidation and integration. Neuron 81:12-34. CrossRef Medline

Van Der Linden M, Wijns C, Von Frenkell R, Coyette F, Seron X (1989) Un questionnaire d'auto-évaluation de la mémoire (QAM). Bruxelles, Belgium: Editest. 
Van Der Werf YD, Altena E, Schoonheim MM, Sanz-Arigita EJ, Vis JC, De Rijke W, Van Someren EJ (2009) Sleep benefits subsequent hippocampal functioning. Nat Neurosci 12:122-123. CrossRef Medline

Van Der Werf YD, Altena E, Vis JC, Koene T, Van Someren EJ (2011) Reduction of nocturnal slow-wave activity affects daytime vigilance lapses and memory encoding but not reaction time or implicit learning. Prog Brain Res 193:245-255. CrossRef Medline

Villeneuve S, Belleville S, Massoud F, Bocti C, Gauthier S (2009) Impact of vascular risk factors and diseases on cognition in persons with mild cognitive impairment. Dement Geriatr Cogn Disord 27:375-381. CrossRef Medline

Walker MP, Brakefield T, Morgan A, Hobson JA, Stickgold R (2002) Practice with sleep makes perfect: sleep-dependent motor skill learning. Neuron 35:205-211. CrossRef Medline
Wallace E, Kim do Y, Kim KM, Chen S, Blair Braden B, Williams J, Jasso K, Garcia A, Rho JM, Bimonte-Nelson H, Maganti R (2015) Differential effects of duration of sleep fragmentation on spatial learning and synaptic plasticity in pubertal mice. Brain Res 1615:116-128. CrossRef Medline

Wechsler D (1997) Wechsler Memory Scale-Third Edition (WMS-III) administration and scoring manual. San Antonio, TX: Psychological Corporation.

Widner B, Ledochowski M, Fuchs D (2000) Sleep disturbances and tryptophan in patients with Alzheimer's disease. Lancet 355:755-756. CrossRef Medline

Yoo SS, Hu PT, Gujar N, Jolesz FA, Walker MP (2007) A deficit in the ability to form new human memories without sleep. Nat Neurosci 10:385-392. CrossRef Medline 